\title{
A comprehensive comparison and classification of routing attacks in wireless sensor networks
}

\author{
Ahmed A. Mohsin * \\ Supervision and Scientific Evaluation Directorate, Ministry of Higher Education and Scientific Research, \\ Baghdad, Iraq
}

\author{
Index Terms \\ Wireless Sensor Network (WSN) \\ Network Layer \\ Security \\ Routing \\ Attacks
}

Received: 26 September 2016

Accepted: 7 March 2017

Published: 21 April 2017

\begin{abstract}
Security has become a primary concern not only for researchers, but also for many users. Wireless Sensor Networks (WSNs) are susceptible to various kinds of attacks, so the need to protect such networks has been increased. There are a number of challenges in WSN security design. Resource constraints such as the ability of processing, low battery life, small memory size and unsecured transmissions make various attacks more dangerous for these networks. Our attention of this paper concentrates on the most typical routing attacks and their capabilities which influence network layer. The attackers can potentially compromise one or more of security goals of the network they attack. This paper is expressing a comparison between routing attacks to find the purpose of the attackers on WSNs' functionality. It classifies and compares them extensively based on different features such as goals, the threat nature, attack function, WSNs' threat site and according to disruption of the route or consumption of the resources. This paper also gives a better understanding of future direction for researchers for designing secure WSNs.
\end{abstract}

(C) 2017 The Author(s). Published by TAF Publishing.

\section{INTRODUCTION}

WSN is designed to check and communicate with other devices over a specific geographic area and control physical environments from remote locations. Today's WSN is used widely in various applications, including Surveillance, environmental monitoring and many others. WSNs are networks formed by many smart, small, energy constrained, self-organizing and low-cost devices. [1]. Sensor networks can deal with different applications and run in unfriendly and uncontrolled environments. However, due to the size of sensor nodes, sensor energy restrictions, changes of the sensor network topology, lack of global identification in sensor nodes and type of tasks expected from the sensors, WSNs' security faces challenges and issues in employing any efficient security scheme different from traditional network security [2]. In section 2, the major design challenges in WSN security are explored. Section 3 reviews the goals of WSN's security. In Sections 4, various types of attacks against network layer are categorized. The classification and comparison of routing attacks about network layer in section 5 are outlined. Finally, section 6 points out the conclusion of the research.

\section{A. Design Challenges of WSN Security}

In WSNs, the understanding of security challenges provides a basis for further works on sensor network's security. WSNs suffer from many design challenges such as resource limitations of sensor nodes and using of insecure communication channels. Various attacks are likely to succeed due to the limited resources available to mitigate the attacks [1], [3], [4], [5]. For example, Zigbex sensor type HBE has an 8-bit, 7.372 MHz ATmega128L RISC MCU with only $4 \mathrm{~Kb}$ SRAM, $128 \mathrm{~Kb}$ flash memories and $512 \mathrm{~Kb}$ flash storage [6]. With such Very Limited Resources, the software built for the sensor node must also be quite small. The pro-

\footnotetext{
* Corresponding author: Ahmed A. Mohsin

†Email: alsaedi_21@yahoo.com
} 
cess by security schemes should be selected based on the following criteria:

A. Power consumption: how much power is required to execute the encryption decryption functions? When implementing a cryptographic function within a sensor node, each computation and transmission of message consume power. Further, the power consumption of sensor nodes is increased due to the security function processing that is required (e.g., encryption, decryption). Each type of encryption/decryption algorithm affects the power consumption at different settings for each algorithm. These settings include different sizes of data blocks and key size.

B. Program memory: the memory required to store the encryption/decryption program. One of the requirements to implement security scheme is to have enough memory space to run security algorithm after loading OS and application code. Moreover, the program memory indicates how much more storage has to be used by the sensor node, which also decreases power.

C. Execution time: the time required to execute the encryption/decryption code. Each cryptographic program has a special execution time which can be measured. The more extra time a sensor node has to be active, the more power is consumed.

D. Program Parameters memory: the required memory size to save the required number of keys used by the encryption/decryption function. Under these criteria, it is important to think about the security requirements very carefully to implement a secure cryptographic algorithm in wireless sensor networks. Applying any security scheme requires transmission of extra bits, hence extra processing, memory and battery power, which are very important resources for the sensors' long life. Table 1 presents various cryptographic algorithms comparison for different parameters like code requirement and cost (time/energy) from [7].

TABLE 1

COMPARISON OF CRYPTOGRAPHIC ALGORITHMS FOR CODE AND COST REQUIREMENTS

\begin{tabular}{llll}
\hline \hline Encryption & Decryption & Cost (time/energy) & Code requirements \\
\hline RSA & RSA & $3.8 \mathrm{~s}$ & 13387B (512 bit key) \\
RC5 & RC5 (Block) & Variable (No. of neighbors) & ROM: 17.9KB RAM: no. of neighbors \\
CTR mode & RC5 (Block) & $7.24 \mathrm{~ms}$ & 2674B \\
CBC mode & Cipher & RC5(C, & RAM: 728B program \\
(Optional) & independent & assembly):0.26ms & space: 7146B \\
\hline \hline
\end{tabular}

\section{B. Security Goals of WSNs}

Implementing security into WSNs is impossible to implement perfectly. WSNs are susceptible to security attacks due to the broadcast nature of transmission medium and placing nodes in a hostile or dangerous environment where they are not physically protected. It is unfeasible to monitor and protect each individual sensor in a large-scale sensor network from physical or logical attack. In this section, the goals of Security in WSN are summarized in table 2 as follows [8], [9].

\section{Network Layer Security Attacks}

The network layer is responsible for routing and forwarding information into the network, such as routing the packets between sensor nodes and routing the packets from a node to the base station. As described earlier, WSNs are susceptible to a large diversity of attacks on the different protocol layers. Particularly, the network layer of WSNs is vulnerable to the different types of attacks that disrupt routing information, create fake routing messages, and degrade the network performance. Attacks in network layer can be classified into two major categories, namely passive and active attacks. Passive attacks are not involved in the protocol, attacker observes protocol, tries to gain information without altering it. Detection of such an attack is not easy since the data and operations of the network itself don't get affected. Active attacks mean active interference of attacker and alter of protocol or data being exchanged in the network. The attacks can also be classified into two categories, namely external attacks and internal attacks. External attacks are defined as attacks from nodes, which do not belong to a WSN; internal attacks occur when legitimate nodes of a WSN behave in unplanned ways. Hence there is need to summarize the major attacks against WSNs, most network layer attacks may be classified as one of the following attacks, as shown in Table 3 [8]. 
TABLE 2

WSN SECURITY GOALS

\begin{tabular}{|c|c|}
\hline Goals & Details \\
\hline Confidentiality & $\begin{array}{l}\text { Confidentiality means ensuring that the content of the data transmitted among sensor nodes is hidden } \\
\text { from everyone in the networks except authorized sensor nodes. Moreover, Identities of the Sensor } \\
\text { nodes and secure key management are extremely important by using encryption. Data should be } \\
\text { restricted within the WSN and not reveal to the sensor nodes neighbors [10]. }\end{array}$ \\
\hline Integrity & $\begin{array}{l}\text { Integrity refers to the ability to ensure the data have not been altered by malicious nodes sent by unau- } \\
\text { thorized parties. Attackers can alter significant data in packets. Even if the confidentiality has been } \\
\text { measured, there is still a possibility that the integrity of data has been compromised by alterations. A } \\
\text { cyclic redundancy checksum (CRC) and checksum are employed for detecting changes in packets. }\end{array}$ \\
\hline Authentication & $\begin{array}{l}\text { Authentication, make sure that the data are initiated from the claimed sender that is exact at the in- } \\
\text { tended receiver. The receiver node must verify if an accepted message comes from a true sender. That } \\
\text { is, the sender and the receiver share a public or secret key to compute the message authentication of } \\
\text { all communicated data. }\end{array}$ \\
\hline Availability & $\begin{array}{l}\text { Which ensures that the desired WSN services and information are available at any time they are } \\
\text { needed. The primarily an availability attack is a denial-of-service attack that makes the network un- } \\
\text { able to prepare service }[24,25] \text {. }\end{array}$ \\
\hline Data Freshness & $\begin{array}{l}\text { Data freshness ensures that the data contents are recent and fresh. This requirement is very important } \\
\text { when there are shared key establishments employed in the design of a network that changes over time } \\
\text { since is no fixed infrastructure among the sensor nodes and the base station in the WSN. }\end{array}$ \\
\hline Secure Localization & $\begin{array}{l}\text { During the implementation of security protocol, the secure localization of each sensor node auto- } \\
\text { matically and accurately is an important property that must be a guarantee. WSN uses the graphical } \\
\text { information to determine the identity of each node. }\end{array}$ \\
\hline Accountability & Unique identification of the entity responsible for any requesting or sending data. \\
\hline Controlled Access & The ability to access certain services or information by only authorized entities. \\
\hline
\end{tabular}

\section{Routing Attacks' Classification}

This section tried to classify and compare the routing attacks based on the nature, threat, location and the type of attack (here classification according to routing disruption attack and/or resource consumption attack is considered); as shown in following table 4 , the most important known routing attacks on WSNs; this table has four columns, including security nature, attack function, WSNs' threat location and according to aiming for disruption of the route or/and consumption of the resources. Our purpose of security nature of attacks includes passive or active. Attack threat shows which security service is attacked, includes confidentiality, integrity, authenticity, availability, data freshness, secure localization, accountability and controlled access. The attacker location (insider or outsider), and based on attack's type on WSN's protocols, include disruption attack and resource consumption attack or both.

Following figure 1 shows the nature of WSN's routing attacks; it compares these attacks based on their nature by presenting the percentage ratio of routing attacks, which is based on passive or active attack; 83 percent of routing attacks' nature is active; 17 percent of routing attacks are passive.

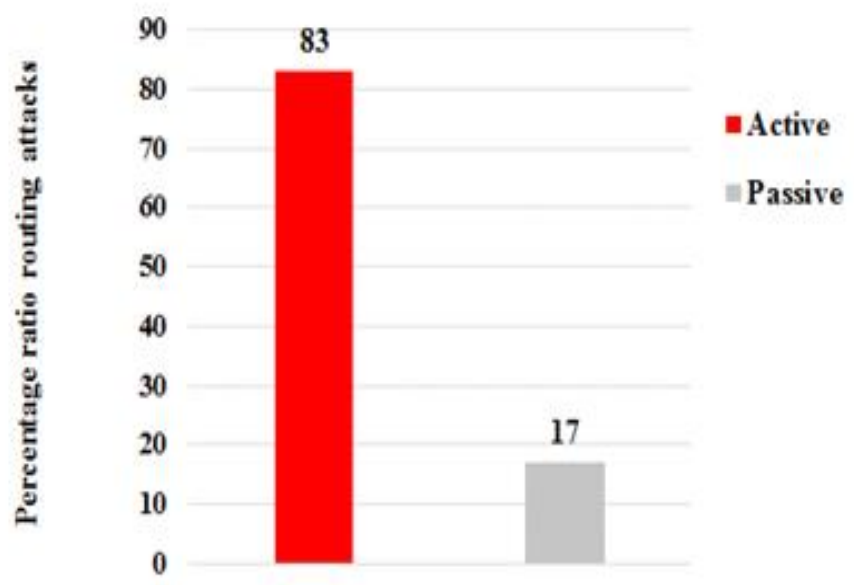

Attack Nature

Fig. 1. The nature of WSN's routing attack 
TABLE 3

ROUTING ATTACKS' DESCRIPTION

\begin{tabular}{|c|c|}
\hline Attacks & Description \\
\hline Blackhole Attack & $\begin{array}{l}\text { It is a type of Denial-of-Service (DoS) attack, malicious node utilizes the routing protocol in order to } \\
\text { advertise itself as having the shortest route to the destination node and hence source nodes select } \\
\text { this shortest path and go through this malicious node and result in drape packets and break commu- } \\
\text { nications between sensor nodes [14]. As soon as the malicious node receives this routing request, } \\
\text { it immediately responds with a false reply to the source node. It replies blindly to every routing re- } \\
\text { quest to convince the source node that it has the shortest path route to the destination. Therefore, the } \\
\text { malicious node becomes source node and controls the whole traffic flows received by it. }\end{array}$ \\
\hline Wormhole Attack & $\begin{array}{l}\text { The wormhole attack is the most severe attack on the routing functionality of wireless networks that } \\
\text { can affect the network even without the knowledge of cryptographic algorithms implemented. It dis- } \\
\text { rupts the communications across the network and is difficult to protect against because they use a } \\
\text { private channel, which is invisible to the WSN. A single or pair of malicious nodes may launch worm- } \\
\text { hole attack. The attacker receives packets at one location in the network, and tunnels those to another } \\
\text { location at a distant location and retransmitting them locally into the WSN through virtual tunnels, } \\
\text { thus creates a wormhole. Wormholes are classified into three types: closed, half open, and open. }\end{array}$ \\
\hline Sybil Attack & $\begin{array}{l}\text { Every actual node in the sensor network has a unique identity. In Sybil attack, an adversary pretends to } \\
\text { be more than one node using forging multiple identities of other legitimate nodes in multiple locations } \\
\text { at the same time by obtaining the legitimate person's IP address, MAC address or public keys [17]. } \\
\text { Sybil attack can be performed for attacking the distributed storage, data aggregation, fair allocation } \\
\text { of resources among the nodes, quality of services in networks and geographical and multipath routing } \\
\text { protocols. }\end{array}$ \\
\hline
\end{tabular}

Selective forward- Selective forwarding attack, a special case of denial of service attack, an attack where the malicious ing attack node refuses to forward packets to certain nodes or drop packets of certain types on the route selectively ensuring they are not propagated any further [18]. In addition, the malicious node may send the packets to the wrong routing path [19], [20]. Selective forwarding attack also behaves like a Blackhole in which it drops every packet it receives. The adversary places itself on the actual data flow path between the two communicating nodes, sends a false routing information and disrupts the network operation and discards some packets.

Neglect and greed Neglect and greed when packets are transferred from a source to destination in between, an attacker attack can force multi-hopping, drops incoming packets arbitrarily and gives undue priority to its own messages. This attack causes degradation of traffic and disturbs the network system, in which nodes may not be capable of sending or receiving packets.

Sinkhole attack In this type of attack, the compromised node tries to place itself on the network flows as a fake base station (BS) and sends fake routing information to its neighbors to attract network traffic to itself with respect to the routing algorithm [21]. Then all the packets pass through it. The aim of an adversary is to prevent base station from acquiring a complete sensing data from nodes in the network [22]. WSNs are mainly vulnerable to sinkhole attacks. Sinkhole attack can be used to launch other series of attacks [23]. The compromised node tries to attract as much traffic as possible in the entire network [24].

HELLO flood attacks The routing protocol consists of hello packets that transmit between sensor nodes. An attacker broadcasts hello message with strong transmission power and acts as a fake sink. The victim nodes think that the malicious node is their neighbor and go through the malicious node as this node provides the shortest path to send packets to the base station. This leads to data congestion and disturbing of the data flow in the network [25]. 
TABLE 3 cont'd...

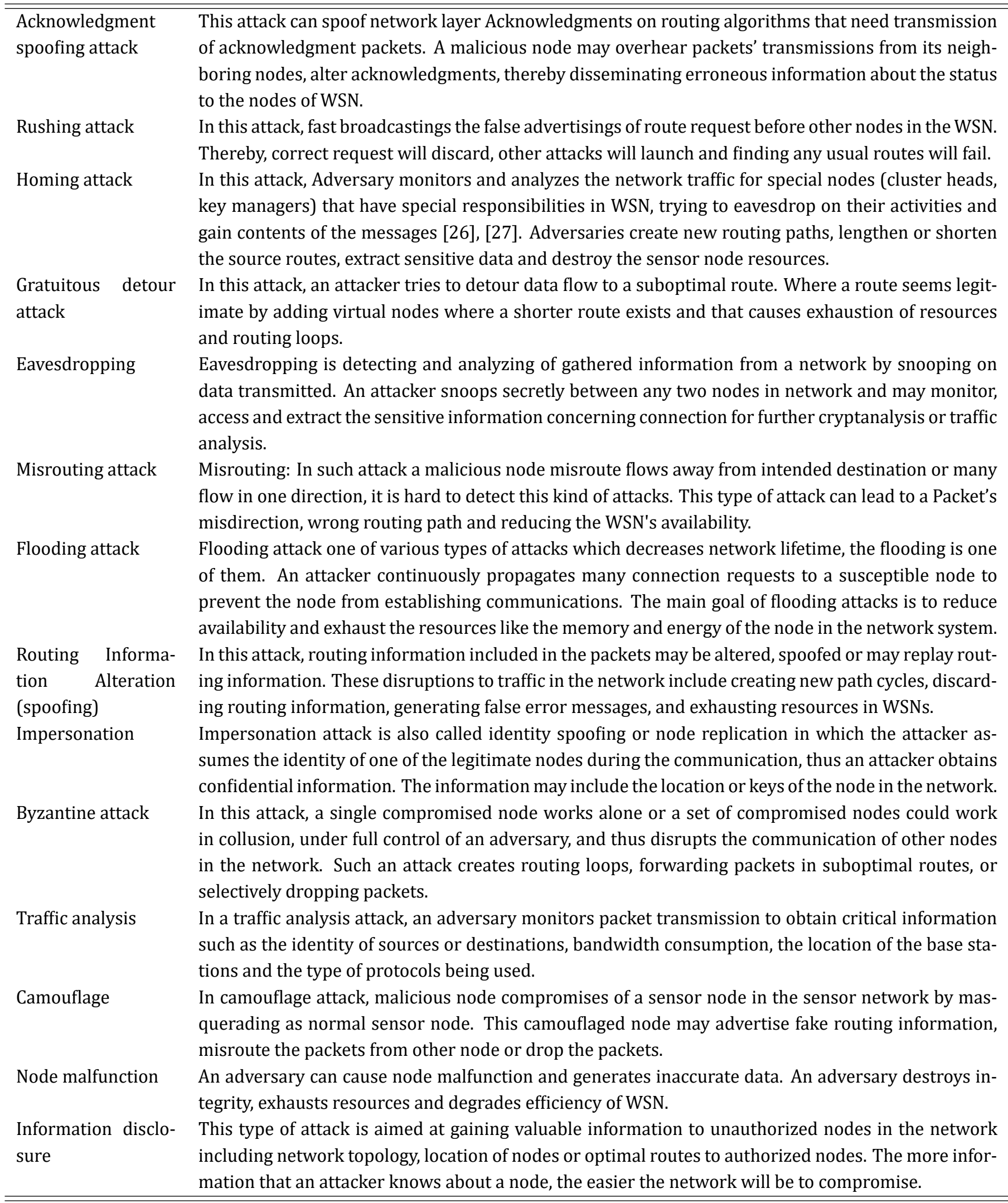


TABLE 3 cont'd..

\begin{tabular}{|c|c|}
\hline nn at- & $\begin{array}{l}\text { lis type of attack occurs when a malicious node provides incorrect reply parameters regarding re- } \\
\text { lest parameters and that leads to broadcasting duplication of address nodes frequently in the net- } \\
\text { ork. }\end{array}$ \\
\hline $\begin{array}{l}\text { Resource Consump- } \\
\text { tion Attack }\end{array}$ & $\begin{array}{l}\text { In resource consumption Attack, the attacker consumes the target network resources like the limited } \\
\text { resource of energy, bandwidth, or memory by broadcasting Route Request packets with a different } \\
\text { broadcast ID. The result of this attack is typically the denial of one or more services offered by the } \\
\text { target nodes. }\end{array}$ \\
\hline IP spoofing attack & $\begin{array}{l}\text { IP spoofing, also known as IP address forgery, a malicious node impersonates a trusted node and } \\
\text { occupies the same IP address in the network, the attacker gains the IP address of a legitimate node. }\end{array}$ \\
\hline $\begin{array}{l}\text { The Packet Replica- } \\
\text { tion Attack }\end{array}$ & $\begin{array}{l}\text { occurs inside the network for the resource. The results are } \\
\text { dth and the power of the network. }\end{array}$ \\
\hline Sleep deprivation & $\begin{array}{l}\text { It's also called Resource consumption attack, the aim of this kind of attack is to consume the resources } \\
\text { (e.g. battery power, bandwidth, etc.) of the specific node of the network so as to minimize the lifetime } \\
\text { of the network, by keeping them busy in routing decisions and forgo their sleep cycles, hence stop } \\
\text { functioning. Attackers broadcasting continuously a large number of route request to the target node. }\end{array}$ \\
\hline $\begin{array}{l}\text { Routing table over- } \\
\text { flow }\end{array}$ & $\begin{array}{l}\text { an attacker tries to create routes to non-exist nodes in the network by injecting false } \\
\text { rol packets to a target node and preventing new routes from being created. }\end{array}$ \\
\hline $\begin{array}{l}\text { Message injection } \\
\text { attack }\end{array}$ & An attacker injects fake control information into the packets. \\
\hline $\begin{array}{l}\text { Message modifica- } \\
\text { tion attack }\end{array}$ & sefore retransmitting. \\
\hline Replay attack & $\begin{array}{l}\text { The adversary performs a replay attack by first intercepting valid control packets and then by resend- } \\
\text { ing those to make other nodes in the network update their routing tables with stale routes. }\end{array}$ \\
\hline
\end{tabular}

Figure 2 shows a comparison of WSNs' routing attacks based on their security threat factors including $\mathrm{Au}-$ thenticity, Availability, Data Freshness, Secure Localization, Accountability and Controlled Access, in percentage ratio; it presents 100 percent of security threats targeting secure localization, 83 percent of security threats targeting data freshness, accountability and controlled access. 27 percent of them are targeting confidentiality.

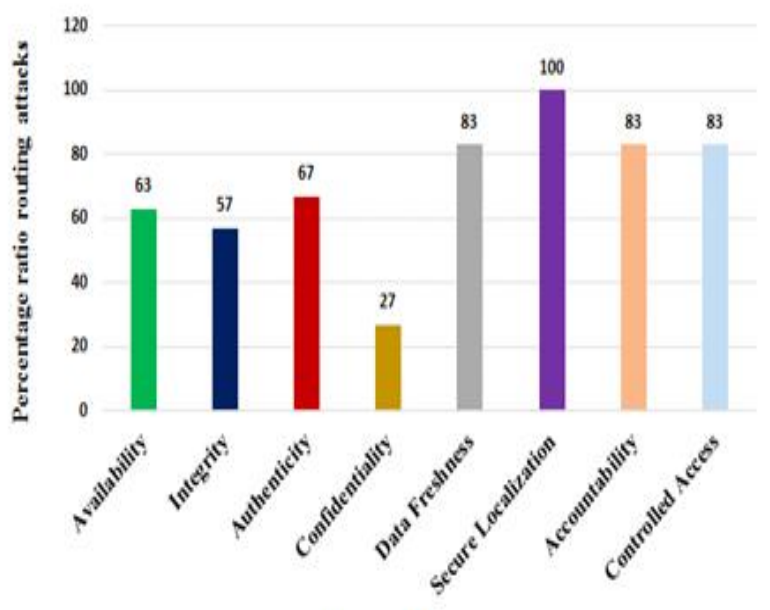

Attack Threat

Fig. 2. The WSN's routing attacks based on their security threats 
TABLE 4

ROUTING ATTACKS' CLASSIFICATION

\begin{tabular}{|c|c|c|c|c|}
\hline Attack & Nature & Attack Threat & Location & Attack Type \\
\hline Blackhole Attack & active & $\begin{array}{l}\text { authenticity, Availability, Data Fresh- } \\
\text { ness, Secure Localization, Accountabil- } \\
\text { ity, Controlled Access }\end{array}$ & Both & Both \\
\hline Wormhole Attack & active & $\begin{array}{l}\text { Confidentiality, authenticity, Data Fresh- } \\
\text { ness, Secure Localization, Accountabil- } \\
\text { ity, Controlled Access }\end{array}$ & Both & Both \\
\hline Sybil Attack & active & $\begin{array}{l}\text { Availability, authenticity, integrity, Data } \\
\text { Freshness, Secure Localization, Account- } \\
\text { ability, Controlled Access }\end{array}$ & Both & Both \\
\hline $\begin{array}{l}\text { Selective forward- } \\
\text { ing attack }\end{array}$ & active & $\begin{array}{l}\text { Availability, integrity, Data Freshness, } \\
\text { Secure Localization, Accountability, Con- } \\
\text { trolled Access }\end{array}$ & inside & Routing Disruption \\
\hline $\begin{array}{l}\text { Neglect and greed } \\
\text { attack }\end{array}$ & active & $\begin{array}{l}\text { Availability, authenticity, Data Fresh- } \\
\text { ness, Secure Localization, Accountabil- } \\
\text { ity, Controlled Access }\end{array}$ & inside & Routing Disruption \\
\hline Sinkhole attack & active & $\begin{array}{l}\text { Availability, integrity, authenticity, Data } \\
\text { Freshness, Secure Localization, Account- } \\
\text { ability, Controlled Access }\end{array}$ & Both & Routing Disruption \\
\hline HELLO flood attacks & active & $\begin{array}{l}\text { Availability, authenticity, Data Fresh- } \\
\text { ness, Secure Localization, Accountabil- } \\
\text { ity, Controlled Access }\end{array}$ & inside & Routing Disruption \\
\hline $\begin{array}{l}\text { Acknowledgement } \\
\text { Spoofing attack }\end{array}$ & active & $\begin{array}{l}\text { Integrity, authenticity, Data Freshness, } \\
\text { Secure Localization, Accountability, Con- } \\
\text { trolled Access }\end{array}$ & Both & Routing Disruption \\
\hline Rushing attack & active & $\begin{array}{l}\text { Availability, integrity, authenticity, Data } \\
\text { Freshness, Secure Localization, Account- } \\
\text { ability, Controlled }\end{array}$ & Access & outside Both \\
\hline Homing attack & passive & Confidentiality, Secure Localization & outside & $\begin{array}{l}\text { Resource Consump- } \\
\text { tion }\end{array}$ \\
\hline $\begin{array}{l}\text { Gratuitous detour } \\
\text { attack }\end{array}$ & active & $\begin{array}{l}\text { Availability, integrity, authenticity, Data } \\
\text { Freshness, Secure Localization, Account- } \\
\text { ability, Controlled Access }\end{array}$ & outside & Both \\
\hline $\begin{array}{l}\text { Eavesdropping } \\
\text { attack }\end{array}$ & passive & Confidentiality, Secure & Localization & outside \\
\hline Misrouting attack & active & $\begin{array}{l}\text { Availability, integrity, authenticity, Data } \\
\text { Freshness, Secure Localization, Account- } \\
\text { ability, Controlled Access }\end{array}$ & outside & Both \\
\hline Flooding attack & active & $\begin{array}{l}\text { Availability, integrity, authenticity, Data } \\
\text { Freshness, Secure Localization, Account- } \\
\text { ability, Controlled Access }\end{array}$ & inside & $\begin{array}{l}\text { Resource Consump- } \\
\text { tion }\end{array}$ \\
\hline $\begin{array}{l}\text { Routing Informa- } \\
\text { tion Alteration } \\
\text { (spoofing) }\end{array}$ & active & $\begin{array}{l}\text { Integrity, authenticity, Data Freshness, } \\
\text { Secure Localization, Accountability, Con- } \\
\text { trolled Access }\end{array}$ & Both & Both \\
\hline
\end{tabular}


TABLE 4 cont'd...

\begin{tabular}{|c|c|c|c|c|}
\hline Impersonation & active & $\begin{array}{l}\text { Availability, integrity, confidentiality, au- } \\
\text { thenticity, Data Freshness, Secure Lo- } \\
\text { calization, Accountability, Controlled Ac- } \\
\text { cess }\end{array}$ & outside & Both \\
\hline Byzantine attack & active & $\begin{array}{l}\text { Availability, Integrity, authenticity, Data } \\
\text { Freshness, Secure Localization, Account- } \\
\text { ability, Controlled Access }\end{array}$ & outside & $\begin{array}{l}\text { Routing Dis- } \\
\text { ruption }\end{array}$ \\
\hline Traffic analysis & passive & Confidentiality, Secure & Localization & outside \\
\hline $\begin{array}{l}\text { Camouflage passive } \\
\text { Confidentiality, } \\
\text { Secure Localization }\end{array}$ & active & $\begin{array}{l}\text { Availability, authenticity, Data Fresh- } \\
\text { ness, Secure Localization, Accountabil- } \\
\text { ity, Controlled Access }\end{array}$ & outside & $\begin{array}{l}\text { Resource } \\
\text { Consump- } \\
\text { tion }\end{array}$ \\
\hline $\begin{array}{lr}\text { outside } & \text { Routing } \\
\text { Disruption } & \text { Node } \\
\text { malfunction } & \end{array}$ & & & & \\
\hline $\begin{array}{l}\text { Information disclo- } \\
\text { sure }\end{array}$ & passive & confidentiality, Secure & Localization & outside \\
\hline State pollution & active & $\begin{array}{l}\text { Availability, integrity, authenticity, Data } \\
\text { Freshness, Secure Localization, Account- } \\
\text { ability, Controlled Access }\end{array}$ & Both & $\begin{array}{l}\text { Routing Dis- } \\
\text { ruption }\end{array}$ \\
\hline $\begin{array}{l}\text { Resource consump- } \\
\text { tion attack }\end{array}$ & active & $\begin{array}{l}\text { Availability, Data Freshness, Secure Lo- } \\
\text { calization, Accountability, Controlled Ac- } \\
\text { cess }\end{array}$ & Both & $\begin{array}{l}\text { Resource } \\
\text { Consump- } \\
\text { tion }\end{array}$ \\
\hline IP spoofing & active & $\begin{array}{l}\text { Availability, integrity, confidentiality, au- } \\
\text { thenticity, Data Freshness, Secure Lo- } \\
\text { calization, Accountability, Controlled Ac- } \\
\text { cess }\end{array}$ & Both & $\begin{array}{l}\text { Routing Dis- } \\
\text { ruption }\end{array}$ \\
\hline $\begin{array}{l}\text { The Packet Replica- } \\
\text { tion Attack }\end{array}$ & active & $\begin{array}{l}\text { Availability, Data Freshness, Secure Lo- } \\
\text { calization, Accountability, Controlled Ac- } \\
\text { cess }\end{array}$ & inside & $\begin{array}{l}\text { Resource } \\
\text { Consump- } \\
\text { tion }\end{array}$ \\
\hline Sleep deprivation & active & $\begin{array}{l}\text { Availability, Data Freshness, Secure Lo- } \\
\text { calization, Accountability, Controlled }\end{array}$ & Access Both & Both \\
\hline $\begin{array}{l}\text { Routing table over- } \\
\text { flow }\end{array}$ & active & $\begin{array}{l}\text { Availability, integrity, authenticity, Data } \\
\text { Freshness, Secure Localization, Account- } \\
\text { ability, Controlled Access }\end{array}$ & outside & Both \\
\hline Message injection & active & $\begin{array}{l}\text { Integrity, authenticity, Data Freshness, } \\
\text { Secure Localization, Accountability, Con- } \\
\text { trolled Access }\end{array}$ & outside & $\begin{array}{l}\text { Routing Dis- } \\
\text { ruption }\end{array}$ \\
\hline $\begin{array}{l}\text { Message modifica- } \\
\text { tion }\end{array}$ & active & $\begin{array}{l}\text { Integrity, authenticity, Data Freshness, } \\
\text { Secure Localization, Accountability, Con- } \\
\text { trolled Access }\end{array}$ & outside & $\begin{array}{l}\text { Routing Dis- } \\
\text { ruption }\end{array}$ \\
\hline Replay attack & active & $\begin{array}{l}\text { Integrity, Data Freshness, Secure Local- } \\
\text { ization, Accountability, Controlled Ac- } \\
\text { cess }\end{array}$ & Both & $\begin{array}{l}\text { Routing Dis- } \\
\text { ruption }\end{array}$ \\
\hline
\end{tabular}


Figure 3 shows the percentage ratio of attacker location; it compares these attacks based on their location; as a result, the occurred percentage of WSNs' routing attacks, in attacker location, are 16 percent insider, 47 percent out of WSNs' range (outsider) and 37 percent from both;

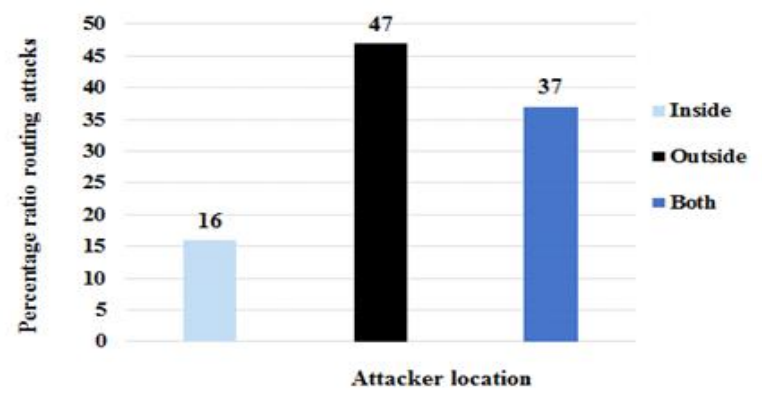

Fig. 3 . Percentage ratio of every routing attack

Figure 4 shows that how much percentage ratio of every routing attack by targeting disruption of the routing or consuming the resources on WSNs. For example, almost 40 percent of these attacks are aiming to disrupt the routing of WSNs, and 17 percent of them are attacking the WSNs' resources, 33 percent of them are aiming both of those types which means to disrupt the route and consume the resources together.

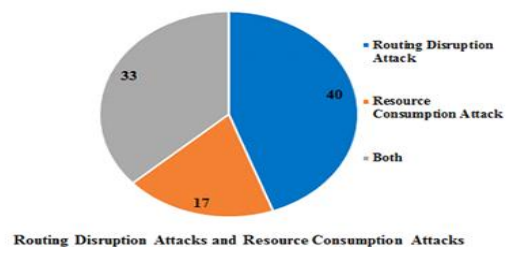

Fig. 4 . The types of WSN's attacks targeting disruption of the routing and/or consuming the resources

\section{CONCLUSION}

Under the limitations of WSNs, it is vital to think about the security requirements very carefully to obtain the best way for securing the transmitted data and extending WSNs in different environments. In this paper, WSN security goals are specified and then well-known routing attacks based on different dimensions are classified and compared. Comparison of classification routing attacks based on the nature, threat, site and the type of attack. The importance of introducing the purpose and classification of well-known routing attacks is to evaluate the risk potential of the attackers and compare it to the cost of protection when designing a proper secure routing protocol. Also, it's showing the effect of the attackers on the WSNs' functionality. However, I wish this comprehensive study could help to guide researchers working on the security issues in the network layer of WSNs.

\section{REFERENCES}

[1] D. G. Padmavathi and M. Shanmugapriya, "A survey of attacks, security mechanisms and challenges in wireless sensor networks," International Journal of Computer Science and Information Security, vol. 4, no. $1 \& 2,2009$.

[2] M. A. Rahman and M. K. Debnath, "An energyefficient data security system for wireless sensor network," in 11th International Conference on Computer and Information Technology, 2008.

DOI: $10.1109 /$ iccitechn.2008.4802984

[3] M. Felamban, B. Shihada and K. Jamshaid, "Optimal node placement in underwater wireless sensor networks," in IEEE 27th International Conference on Advanced Information Networking and Applications (AINA), Barcelona, Spain 2013.

DOI: $10.1109 /$ aina.2013.40

[4] S. Saleem, S. Ullah and H. S. Yoo, "On the security issues in wireless body area networks," JDCTA, vol. 3, no. 3, pp. 178-184, 2009.

DOI: $10.4156 /$ jdcta.vol3.issue3.22

[5] J. Ben-Othman and B. Yahya, "Energy efficient and QoS based routing protocol for wireless sensor networks," Journal of Parallel and Distributed Computing, vol. 70, no. 8, pp. 849-857, 2010.

DOI: $10.1016 / j$.jpdc.2010.02.010

[6] HBE-Zigbex, "Ubiquitous sensor network," Zigbex manual [Online]. Available: https://goo.gl/aWxuKk

[7] G. Sharmaa, S. Balaa and A. Vermaa, "Security frameworks for wireless sensor networks-review," Procedia Technology, vol. 6, pp. 978-987, 2012. DOI: 10.1016/j.protcy.2012.10.119

[8] P. Mohanty, S. Panigrahi, N. Sarma and S. S. Satapathy, "Security issues in wireless sensor network data gathering protocols: A survey," Journal of Theoretical and Applied Information Technology, vol. 13, no. 1/2, pp. 14-27, 2010.

[9] X. Chen, K. Makki, K. Yen and N. Pissinou, "Sensor network security: A survey," IEEE Communications Surveys \& Tutorials, vol. 11, no. 2, pp. 52-73, 2009. DOI: $10.1109 /$ SURV.2009.090205

[10] K. Ren, S. Yu, W. Lou and Y. Zhang, "Multi-user 
broadcast authentication in wireless sensor networks," IEEE Transactions on Vehicular Technology, vol. 58, no. 8, pp. 4554-4564, 2009.

DOI: $10.1109 /$ TVT. 2009.2019663

[11] L. B. Oliveira, D. F. Aranha, C. P. Gouvêa, M. Scott, D. F. Câmara, J. López and R. Dahab, "Tiny PBC: Pairings for authenticated identitybased non- interactive key distribution in sensor networks," Computer Communications, vol. 34, no. 3, pp. 485- 493, 2011.

DOI: $10.1016 /$ j.comcom.2010.05.013

[12] C. Gomez and J. Paradells, "Wireless home au tomation networks: A survey of architectures and technologies," IEEE Communications Magazine, vol. 48, no. 6, pp. 92-101, 2010.

DOI: $10.1109 /$ MCOM.2010.5473869

[13] K. Sunitha and H. Chandrakanth, "A survey on security attacks in wireless sensor network," International Journal of Engineering Research and Applications (IJERA), vol. 2, no. 4, pp. 1684-1691, 2012.

[14] S. Tamilarasan, "Securing and preventing AODV routing protocol from black hole attack using counter algorithm," International Journal of Engineering Research and Technology, vol. 1, no. 5, pp. 1-5, 2012.

[15] M. A. Azer, S. M. El-Kassas and M. S. El-Soudani, "An innovative approach for the wormhole attack detection and prevention in wireless ad hoc networks," in International Conference on Networking, Sensing and Control (ICNSC), 2010.

DOI: 10.1109/ICNSC.2010.5461523

[16] B. Bhargava, R. de Oliveira, Y. Zhang and N. C. Idika, "Addressing collaborative attacks and defense in ad hoc wireless networks," in 29th IEEE International Conference on Distributed Computing Systems Workshops, 2009.

DOI: $10.1109 /$ icdcsw.2009.77

[17] D. N. Sushma and V. Nandal, "Security threats in wireless sensor networks," IJCSMS International Journal of Computer Science \& Management Studies, vol. 11, no. 01, pp. 59-63, 2011.

[18] L. K. Bysani and A. K. Turuk, "A survey on selective forwarding attack in wireless sensor net works," in International Conference on Devices and Communications (ICDeCom), 2011.

DOI: 10.1109 /icdecom.2011.5738547
[19] W. Xin-Sheng, Z. Yong-zhao, X. Shu-ming and W. Liang-min, "Lightweight defense scheme against selective forwarding attacks in wireless sensor networks," in IEEE International Conference on CyberEnabled Distributed Computing and Knowledge Discovery, 2009. D0I: 10.1109/cyberc.2009.5342206

[20] K. Venkatraman, J. VijayDaniel and G. Murugaboopathi, "Various attacks in wireless sensor network: Survey," International Journal of Soft Computing and Engineering, vol. 3, no. 1, pp. 208-211. 2013.

[21] A. Pandey and R. C. Tripathi, "A survey on wireless sensor networks security," International Journal of Computer Applications, vol. 3, no. 2, pp. 43-49, 2010. DOI: $10.5120 / 705-989$

[22] P. Samundiswary, D. Sathian and P. Dananjayan, "Secured greedy perimeter stateless routing for wireless sensor networks," International Journal of Ad hoc, Sensor \& Ubiquitous Computing (IJASUC), vol. 1, no. 2, 9-20, 2010.

DOI: 10.5121 ijasuc.2010.1202

[23] L. Rajakumaran and R. Thamarai Selvi, "Detection techniques of sinkhole attack in WSNs: A survey," International Journal of Engineering Science Invention, vol. 3, no. 6, pp. 12-14, 2014.

[24] L. Teng and Y. Zhang, "SeRA: A secure routing algorithm against sinkhole attacks for mobile wireless sensor networks," in IEEE Conference on Computer Modeling and Simulation, 2010.

DOI: $10.1109 /$ iccms.2010.95

[25] Pooja, M and Singh, Y, "Security issues and sybil attack in wireless sensor networks," International Jour nal of P2P Network Trends and Technology, vol. 1, no. 3, pp. 7-13, 2013.

[26] S. Mohammadi, R. A. Ebrahimi and H. Jadidoleslamy, "A comparison of routing attacks on wireless sensor networks," International Journal of Information Assurance and Security (JIAS), vol. 6, pp. 195-215, 2011.

[27] S. N. Cubero, S. McLernon and A. Sharpe, "Overspeeding warning system using wireless communications for road signs and vehicles," Journal of Advances in Technology and Engineering Studies, vol. 2, no. 5, pp. 140-155, 2016.

— This article does not have any appendix. - 